Published in final edited form as:

Dalton Trans. 2018 May 08; 47(18): 6351-6360. doi:10.1039/c8dt00805a.

\title{
An Electron Transfer Driven Magnetic Switch: Ferromagnetic Exchange and Spin Delocalization in Iron Verdazyl Complexes
}

\author{
David J. R. Brook ${ }^{\mathrm{a}}$, Connor Fleming ${ }^{\mathrm{a}}$, Dorothy Chung ${ }^{\mathrm{a}}$, Cardius Richardson ${ }^{\mathrm{a}}$, Servando \\ Ponce $^{\mathrm{a}}$, Raja Das ${ }^{\mathrm{b}}$, Hariharan Srikanth ${ }^{\mathrm{b}}$, Ranko Heindl ${ }^{\mathrm{c}}$, and Bruce C. Noll ${ }^{\mathrm{d}}$ \\ aDepartment of Chemistry, San José State University, One Washington Square, San José, CA \\ 95192, USA \\ bDepartment of Physics, University of South Florida, Tampa, Florida 33620, USA \\ 'Department of Physics and Astronomy, San José State University, One Washington Square, San \\ José, CA 95192, USA \\ ${ }^{\mathrm{d} B r u k e r}$ AXS inc. Madison, Wisconsin. USA
}

\begin{abstract}
The verdazyl 'pincer' ligand, 1-isopropyl-3,5-dipyridyl-6-oxoverdazyl (dipyvd), coordinates iron to form a series of pseudooctahedral coordination compounds $\left[\mathrm{Fe}(\operatorname{dipyvd})_{2}\right]^{\mathrm{n}+}(\mathrm{n}=0-3)$. In the case where $\mathrm{n}=2$, the molecular geometry and physical and spectral properties are consistent with a low spin ( $\mathrm{S}=0$ ) iron (II) ion coordinated by two ferromagnetically coupled radical ligands. Upon one electron reduction, the room temperature effective magnetic moment of the complex jumps from $\mu_{\mathrm{eff}}=2.64$ to $\mu_{\mathrm{eff}}=5.86$ as a result of spin crossover of the iron atom combined with very strong ferromagnetic coupling of the remaining ligand centered unpaired electron with the metal center. The sign of the exchange is opposite to that observed in other high spin iron/radical ligand systems and appears to be a result of delocalization of the ligand unpaired electron across the whole molecule. The large change in magnetic properties, combined with a delocalized electronic structure and accessible redox potentials, suggests the utility of this and related systems in the development of novel molecular spintronic devices
\end{abstract}

\section{TOC image}

A single electron reduction of an iron bis(verdazyl) complex results in a large change in spin multiplicity resulting from a combination of spin crossover and exceptionally strong ferromagnetic exchange.

\footnotetext{
Electronic Supplementary Information (ESI) available: Detailed synthetic procedures, Crystallographic data for $\left[\mathrm{Fe}\left(\mathrm{dipyvd}_{2}\right]^{+} \mathrm{PF}_{6}{ }^{-}\right.$ and both forms of $\left[\mathrm{Fe}(\text { dipyvd })_{2}\right]^{2+}\left(\mathrm{PF}_{6}^{-}\right)_{2}$ IR spectra for $\left[\mathrm{Fe}(\text { dipyvd })_{2}\right]^{+} \mathrm{PF}_{6}^{-}$and $\left[\mathrm{Fe}(\text { dipyvd })_{2}\right]^{2+}\left(\mathrm{PF}_{6}{ }^{-}\right)_{2}$. Spectroelectrochemical data for the full $\left[\mathrm{Fe}(\text { dipyvd })_{2}\right]^{\mathrm{n}+}$ series with spectra corresponding to each specific oxidation state. ${ }^{1} \mathrm{H}$ NMR and ${ }^{13} \mathrm{C}$ NMR spectra for 2. Results of DFT and TDDFT calculations including atomic coordinates excitation energies. See DOI: 10.1039/x0xx00000x

Conflicts of interest

There are no conflicts to declare
} 


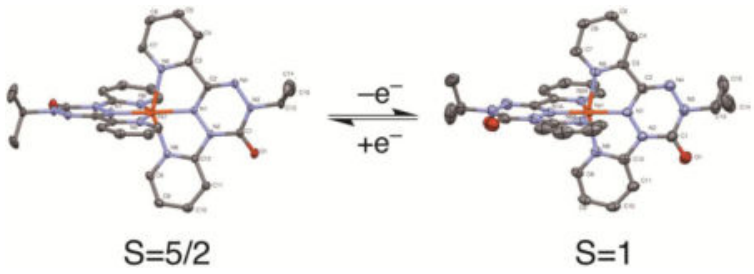

\section{Introduction}

Molecular switches have long been sought after as a way of introducing complex functionality into man-made molecular systems. ${ }^{1}$ Switchable molecules can conceivably be utilized for high density information storage, ${ }^{2}$ as well as components of more complex devices, ultimately leading to ideas such as molecular computing or molecular machines. Various mechanisms have been utilized to switch molecules between states including the manipulation of supramolecular interactions and formation and cleavage of covalent bonds as well as more subtle changes in electronic structure such as spin crossover ${ }^{3,4}$ and valence tautomerism. ${ }^{5}$ The last two phenomena are particularly interesting because they can result in changes in spin multiplicity and magnetic properties, which may, in turn, be coupled into spintronic applications.

Spin crossover and valence tautomerization both involve species with two (or more) isomeric forms that are close in energy but differ in electronic distribution. In the case of spin crossover, isomers typically differ in the occupation of $d$ orbitals on a single transition metal ion, resulting in differences in spin multiplicity. Most often the transition between forms is achieved thermally, though there are some notable photochemical examples. ${ }^{6}$ Observation of spin crossover requires a subtle balance of metal-ligand interactions to enable thermal accessibility of the higher energy state, and can consequently be dependent on such ephemeral properties such as counterion and crystal packing. In certain cases, intermolecular interactions within a crystal structure can lead to cooperative effects and hysteresis of the transition between one form and the other. ${ }^{4}$

In valence tautomers, the isomers differ in the distribution of electrons over different parts of the molecule. ${ }^{7,8}$ Typically this is between metal and ligand, though purely organic examples are known. ${ }^{9}$ Transition between isomers is not necessarily accompanied by a change in spin multiplicity. As in spin crossover, switching between isomers can be induced thermally or photochemically. Valence tautomers may be considered special cases of mixed valence systems in which the relative stability of different electronic configurations is dependent upon the molecular environment, allowing one or the other electronic configuration to dominate depending upon the circumstances.

The problem with both of these approaches to molecular switches is obtaining a sufficient energy barrier to prevent thermal interconversion of isomers under ambient conditions. In some cases a sufficient barrier arises from cooperative interactions between molecules in a crystal lattice, but such a mechanism is not operational at the molecular level. An alternative is to utilize chemical changes to drive the switching of magnetic properties. Though the species involved are no longer strictly tautomers, changes in spin multiplicity can also be 
achieved through changes in $\mathrm{pH}^{10-12}$ or oxidation/reduction. In the latter case, one electron oxidation or reduction must give at the least a change in spin multiplicity of $\pm 1 / 2$, but it is possible in some cases for the additional electron to provide new exchange pathways or change ligand properties to induce spin crossover. For example in the system described by Ito $^{13}$ oxidation of a phenylenediamine linker results in a ferromagnetic exchange pathway between attached nitronyl nitroxide radicals. More recently, Harris reported a system with quinonoid ligands in which delocalized electrons mediated long range ferromagnetic exchange between $\mathrm{Fe}^{3+}$ ions, ${ }^{14}$ and an extended $\mathrm{Mn}^{3+}$ system in which ligand reduction results in an increase in magnetic exchange and a parallel increase in conductivity mediated by delocalized electrons. ${ }^{15}$ Iron-polypyridyl systems are frequently close to the spin crossover limit so that small chemical changes to the ligand can induce spin crossover. For example reduction of both $\left[\mathrm{Fe}(\text { terpy })_{2}\right]^{2+}$ and $\left[\mathrm{Fe}(\mathrm{MeOPDI})_{2}\right]^{2+}\left(\right.$ terpy $=2,2^{\prime} ; 6^{\prime}, 2^{\prime \prime}-$ terpyridine, MeOPDI=2,6-bis[1-(4-methoxyphenylimino)ethyl]pyridine, chart 1) occurs on the ligand, reducing the pi-acceptor character of the ligand and ultimately resulting in a transition from low spin to high spin at the metal center. ${ }^{16,17}$ These latter systems are appealing for incorporation in molecular or spintronic devices because the change in spin multiplicity at the metal center is very large ( $S=0$ to $S=2$ ) amplifying the influence of a single electron. However the potential at which reduction occurs is very low, resulting in species that are extremely air sensitive and often contaminated with metallic iron. ${ }^{16} \mathrm{By}$ using more electron deficient ligands, ${ }^{18}, 19$ it may be possible to move such switching events to a more accessible potential window giving species with greater potential application in molecular devices.

6-Oxoverdazyls are stable redox active heterocyclic radical species that feature structural versatility through varied substituents and can be incorporated directly into polypyridyl type ligands. ${ }^{20}$ Recent studies have also shown that verdazyls are redox active, both as uncoordinated species ${ }^{21}$ and bound to metal ions. ${ }^{22-24}$ In 2010 we reported the synthesis of a neutral terpyridine analog, 1-isopropyl-3,5-dipyridyl-6- oxoverdazyl (dipyvd) that incorporates the verdazyl at the center of the ligand structure resulting in a remarkably strong magnetic interaction with a coordinated nickel ion. ${ }^{25}$ Because of the single electron in an antibonding orbital, this ligand might be considered isolobal with the terpyridine anion suggesting that the iron compound of this ligand is a promising place to look for unusual spin crossover effects, including redox induced spin changes and the influence of magnetic coupling on the spin crossover effect itself. We report here on the synthesis and properties of $\left[\mathrm{Fe}(\text { dipyvd })_{2}\right]^{1+/ 2+}$, and in particular the influence of redox reactions on the magnetic properties of this system.

\section{Results}

\section{Synthesis}

Our initial studies with the verdazyl ligand dipyvd used stoichiometric combination of radical and nickel triflate to give the corresponding homoleptic coordination compound (Scheme 1). ${ }^{25}$ Though this approach also works with ferrous triflate giving $\left[\mathrm{Fe}(\mathrm{dipyvd})_{2}\right]^{2+}$ $\left(\mathrm{PF}_{6}{ }^{-}\right)_{2}$, we (and others ${ }^{26}$ ) have found that using the leucoverdazyl species 2 in the synthesis gives more reproducible results. Leucoverdazyl $\mathbf{2}$ is conveniently obtained through partial 
oxidation of the corresponding tetrazane (scheme 2). Combination of 2 with ferric ammonium sulfate in methanol/water results in formation of the monocationic species $\left[\mathrm{Fe}(\text { dipyvd })_{2}\right]^{+}$, which was precipitated as the hexafluorophosphate salt. Subsequent oxidation of $\left[\mathrm{Fe}(\text { dipyvd })_{2}\right]^{+}\left(\mathrm{PF}_{6}{ }^{-}\right)$with one equivalent of $\mathrm{AgPF}_{6}$ in dichloromethane provides a more convenient route to $\left[\mathrm{Fe}(\operatorname{dipyvd})_{2}\right]^{2+}\left(\mathrm{PF}_{6}{ }^{-}\right)_{2}$.

\section{Crystallography}

Single crystals of both $\left[\mathrm{Fe}(\text { dipyvd })_{2}\right]^{+}\left(\mathrm{PF}_{6}^{-}\right)$and $\left[\mathrm{Fe}(\text { dipyvd })_{2}\right]^{2+}\left(\mathrm{PF}_{6}^{-}\right)_{2}$ were grown from acetonitrile/ether and studied by $\mathrm{X}$-ray diffraction. Thermal ellipsoid plots are shown in figure 1. Key bond lengths are listed in table 1. Additionally in table 1 we have listed pertinent bond lengths from the structure of a recently reported coordinated verdazyl anion. 27

Monocation $\left[\mathrm{Fe}(\text { dipyvd })_{2}\right]^{+}\left(\mathrm{PF}_{6}{ }^{-}\right)$crystallized in space group $I \overline{4}$ with the iron atoms lying on an $\mathrm{S}_{4}$ axis which relates the two ligands. Iron-ligand distances are typical for a high spin $\mathrm{Fe}^{2+}$ species. The verdazyl ring has marginally longer bond lengths and deviates further from planarity than the verdazyl ring in the corresponding dicationic species (vide infra).

Two polymorphs of the dication salt $\left[\mathrm{Fe}(\text { dipyvd })_{2}\right]^{2+}\left(\mathrm{PF}_{6}{ }^{-}\right)_{2}$ were identified; a tetragonal form, (space group $P \overline{4} 2{ }_{1} c$ ) isomorphic with the previously reported nickel species, ${ }^{25}$ and a triclinic form (space group $P \overline{1}$ ). Metal-ligand bond lengths in triclinic form are markedly shorter than those in the monocation and comparable to those in $\left[\mathrm{Fe}(\text { terpy })_{2}\right]^{2+}$ consistent with low spin $\mathrm{Fe}^{2+}$. Dimensions of the verdazyl ligand are comparable (within experimental error) to those in the corresponding nickel complex, ${ }^{25}$ consistent with a radical ligand. In the tetragonal form, bond lengths are less well characterized because of orientational disorder in the structure. Nevertheless they do not appear to be significantly different than the triclinic form. Data for the tetragonal form are provided in the supporting material.

\section{Vibrational Spectroscopy}

The IR spectrum of $\left[\mathrm{Fe}(\text { dipyvd })_{2}\right]^{2+}$ shows a single $\mathrm{C}=\mathrm{O}$ stretch at $1725 \mathrm{~cm}^{-1}$, and the spectrum is overall very similar to that for the corresponding nickel species. Monocation $\left[\mathrm{Fe}(\text { dipyvd })_{2}\right]^{+}$also shows a single $\mathrm{C}=\mathrm{O}$ stretch but at the somewhat lower frequency of $1676 \mathrm{~cm}^{-1}$ suggesting higher electron density on the verdazyl ring, but also indicating that both rings are identical on the vibrational timescale. IR spectra of both species are provided in the supporting information.

\section{Magnetic Susceptibility}

Magnetic susceptibilities of solid samples of $\left[\mathrm{Fe}(\text { dipyvd })_{2}\right]^{2+}\left(\mathrm{PF}_{6}{ }^{-}\right)_{2}$ and $\left[\mathrm{Fe}(\text { dipyvd })_{2}\right]^{+}$ $\mathrm{PF}_{6}{ }^{-}$were measured over the range 5-300K. The monocation, $\left[\mathrm{Fe}(\text { dipyvd })_{2}\right]^{+} \mathrm{PF}_{6}{ }^{-}$showed near ideal Curie law behavior; a plot of $\chi$ vs. 1/T gave a straight line with slope of $4.3\left(\mu_{\mathrm{eff}}\right.$ $=5.86$ ) consistent with an $\mathrm{S}=5 / 2$ system with $g=1.98$ (ESI). Plotting $\chi_{\text {para }} \mathrm{T}$ vs $\mathrm{T}$ (Figure 2) showed a small drop in the value of $\chi_{\mathrm{para}} \mathrm{T}$ at very low temperature that could be due to zero field splitting or a weak intermolecular antiferromagnetic interaction. 
The dication, $\left[\mathrm{Fe}(\text { dipyvd })_{2}\right]^{2+}\left(\mathrm{PF}_{6}{ }^{-}\right)_{2}$ showed slightly more complex behavior. A simple Curie plot showed a distinct curvature so a plot of $\chi_{\text {para }} \mathrm{T}$ vs $\mathrm{T}$ was used for further analysis. At $300 \mathrm{~K}$, the solid material has $\chi_{\text {para }} \mathrm{T}=0.87\left(\mu_{\text {eff }}=2.64\right)$, slightly higher than the value expected for two uncoupled spins with $g=2$. Lowering the temperature resulted in an increase in $\chi_{\text {para }} \mathrm{T}$, reaching a maximum of 0.98 near $50 \mathrm{~K}$. At lower temperatures $\chi_{\text {para }} \mathrm{T}$ decreases to reaching 0.65 at $5 \mathrm{~K}$ (Figure 2). The data was modeled as a singlet/triplet equilibrium using the spin Hamiltonian $\mathbf{H}=-\boldsymbol{J} \mathbf{S}_{\mathbf{1}} \cdot \mathbf{S}_{\mathbf{2}}$ modified with an additional term $\mathbf{J}^{\prime}$ for intermolecular interaction to account for the drop in $\chi_{\text {para }} \mathrm{T}$ at low temperature. This gives, for $\chi_{\text {para }} T$ :

$$
\chi T=\frac{3}{\left(3+e^{-J / k T}\right)} \cdot\left(1-J^{\prime} / k T\right)^{-1}
$$

Optimization of the parameters $J$ and $J^{\prime}$ gave $J=+164(4) \mathrm{cm}^{-1}$, and $J^{\prime}=-1.2(1) \mathrm{cm}^{-1}$ holding $g$ fixed at 2.00 .

\section{Electronic Spectroscopy}

The electronic spectrum of $\left[\mathrm{Fe}(\text { dipyvd })_{2}\right]^{2+}$ shows several bands in the $550-600 \mathrm{~nm}$ range corresponding to those observed in the corresponding nickel complex, but is dominated by a strong NIR band near $850 \mathrm{~nm}$. In both dichloromethane and acetonitrile solution the electronic spectrum of $\left[\mathrm{Fe}(\text { dipyvd })_{2}\right]^{+}$is dominated by a strong, asymmetric band in the near IR with a maximum at $1000 \mathrm{~nm}$ (Figure 3). Spectra of $\left[\mathrm{Fe}(\text { dipyvd })_{2}\right]^{2+}$ and $\left[\mathrm{Fe}(\text { dipyvd })_{2}\right]^{+}$ were reproduced with spectroelectrochemical measurements (vide infra).

\section{Electrochemistry}

Cyclic voltammetry of both species in acetonitrile gave the same voltammogram confirming the relationship between them. The data shows three reversible one-electron processes at $-0.19,+0.40$ and $+1.12 \mathrm{~V}$ vs. SCE corresponding to the processes $\left[\mathrm{Fe}(\operatorname{dipyvd})_{2}\right]^{0 /}$ $\left[\mathrm{Fe}(\text { dipyvd })_{2}\right]^{+},\left[\mathrm{Fe}(\text { dipyvd })_{2}\right]^{+} /\left[\mathrm{Fe}(\text { dipyvd })_{2}\right]^{2+}$ and $\left[\mathrm{Fe}(\text { dipyvd })_{2}\right]^{2+} /\left[\mathrm{Fe}(\text { dipyvd })_{2}\right]^{3+}($ Figure $4)$.

UV spectra of the species were determined through spectroelectrochemistry and are provided in the supporting material. Spectra taken at $0.2 \mathrm{~V}$ and $0.7 \mathrm{~V}$ correspond to those recorded for $\left[\mathrm{Fe}(\text { dipyvd })_{2}\right]^{+} \mathrm{PF}_{6}{ }^{-}$and $\left[\mathrm{Fe}(\text { dipyvd })_{2}\right]^{2+}\left(\mathrm{PF}_{6}{ }^{-}\right)_{2}$ respectively.

\section{Computational Studies}

To further support our understanding of these complex systems, we have performed DFT and TDDFT calculations on $\left[\mathrm{Fe}(\text { dipyvd })_{2}\right]^{\mathrm{n}+}$ at several different oxidation states and spin multiplicities. Following the example of England et al, ${ }^{16}$ we obtained optimized geometries using the BP86 functional, starting from the crystallographic geometry. Key optimized bond lengths are reported in table 2 . For $\left[\mathrm{Fe}(\text { dipyvd })_{2}\right]^{+}$, the optimized coordination geometry at the metal was dependent upon the spin multiplicity, with $S=5 / 2$ giving a geometry close to the experimental values, while $S=3 / 2$ or $S=1 / 2$ giving geometries (ESI) more consistent with a low spin metal center. Subsequent single point energy DFT and TDDFT calculations using the B3LYP hybrid functional were used to obtain energies and excitation energies. To 
provide a point of comparison we have also performed these calculations on the previously reported $\mathrm{Ni}^{2+}$ species (reported in the supporting information). Calculated excitation energies are plotted on the UV-vis spectra in figure 3. The calculated excitation energies reproduce the general spectral features reasonably well, though the computed energy for the prominent MLCT band in $\left[\mathrm{Fe}(\text { dipyvd })_{2}\right]^{2+}$ is $1400 \mathrm{~cm}^{-1}$ higher than the experimental value. Calculated distribution of spin density is shown in figure 5 . The broken symmetry formalism ${ }^{28}$ was used to estimate exchange parameters in these species giving $J=+240 \mathrm{~cm}^{-1}$ for $\left[\mathrm{Fe}(\text { dipyvd })_{2}\right]^{2+}$ and $J=+1470 \mathrm{~cm}^{-1}$ for $\left[\mathrm{Fe}(\text { dipyvd })_{2}\right]$

\section{Discussion}

The electronic configuration of the dicationic species $\left[\mathrm{Fe}(\operatorname{dipyvd})_{2}\right]^{2+}$ is straightforward. Bond lengths (for both ligand and metal ion) are consistent with low spin $\mathrm{Fe}^{2+}$ coordinated to neutral radical ligands. This is also consistent with the IR (which overlays almost exactly with that from the corresponding $\mathrm{Ni}^{2+}$ complex) and room temperature magnetic susceptibility corresponding to two $\mathrm{S}=1 / 2$ ligands and a low spin metal center. Magnetic exchange between the two radical ligands is relatively large $\left(\mathrm{J}=+164 \mathrm{~cm}^{-1}\right)$ and ferromagnetic and consistent with the interligand exchange observed in $\left[\mathrm{Ni}(\operatorname{dipyvd})_{2}\right]^{2+}(\mathrm{J}=$ $\left.+160 \mathrm{~cm}^{-1}\right) \cdot{ }^{25}$ DFT calculations support this interpretation, with a predicted ferromagnetic exchange and spin density on the triplet distributed over both ligands and extending onto the metal ion. Ferromagnetic exchange is expected when there is no overlap between interacting singly occupied orbitals and thus might be expected here because the two ligands are perpendicular; however the relevant orbitals are not strictly orthogonal (vide infra) and so the overall ferromagnetic interaction is best thought of as the result of competing ferromagnetic and antiferromagnetic exchange pathways in which the ferromagnetic exchange proves the stronger. The strength of the ferromagnetic interaction is enhanced by overlap of the ligand SOMO with the metal $d_{\mathrm{xz}}$ and $d_{\mathrm{yz}}$ orbitals which is reflected in the distribution of spin density (Figure 5). The interpretation of the UV-vis spectrum takes a little more effort. In our previous publication we speculated that the prominent visible bands near $600 \mathrm{~nm}$ in the corresponding Ni complex had some metal-ligand charge-transfer character. ${ }^{25}$ Similar, but much weaker, bands are visible in the spectrum of $\left[\mathrm{Fe}(\text { dipyvd })_{2}\right]^{2+}$, but TDDFT calculations indicate that these bands (in both $\left[\mathrm{Fe}(\text { dipyvd) })_{2}\right]^{2+}$ and $\left[\mathrm{Ni}(\text { dipyvd })_{2}\right]^{2+}$ ) are largely intraligand in nature; the strong red shift in comparison to the ligand results from lowering the ligand SOMO as a result of interaction with the metal ion.

Conversely TDDFT calculation strongly suggests that the strong absorption of $\left[\mathrm{Fe}(\text { dipyvd })_{2}\right]^{2+}$ near $800 \mathrm{~nm}$ has significant MLCT character.

Things are more ambiguous for the monocationic species $\left[\mathrm{Fe}(\mathrm{dipyvd})_{2}\right]^{+}$. The metal-ligand distances are markedly longer than in the dication suggesting a high spin metal ion.

Magnetic susceptibility is consistent with an $\mathrm{S}=5 / 2$ ground state, which is the only populated state even at $300 \mathrm{~K}$. The reduction in $\mathrm{C}=\mathrm{O}$ stretching frequency points to additional electron density on the verdazyl ring, but the single $\mathrm{C}=\mathrm{O}$ bond stretch in the IR in both the solid state and solution indicates that the molecule is symmetrical and the two ligands have the same oxidation state. 
Two localized descriptions are consistent with two equivalent ligands; high spin $\mathrm{Fe}^{3+}\left(\mathrm{d}^{5}\right.$, $\mathrm{S}=5 / 2$ ) coordinated to two diamagnetic leucoverdazyl anion ligands, or high spin $\mathrm{Fe}^{+}\left(\mathrm{d}^{7}\right.$, $\mathrm{S}=3 / 2$ ) coordinated to two verdazyl ligands, with strong ferromagnetic coupling between all three spin centers giving an overall $\mathrm{S}=5 / 2$ ground state. Neither of these descriptions are completely satisfactory though. The verdazyl ligands are distorted from planarity and the bond lengths elongated, compared to neutral coordinated verdazyls, but the distortion is not as large as observed in coordinated leucoverdazyl anions. ${ }^{27}$ This is clear from inspection of the data in table 2, where the N-N distances in $\left[\mathrm{Fe}(\text { dipyvd })_{2}\right]^{+}$are between those of the neutral verdazyl ligands in $\left[\mathrm{Fe}(\text { dipyvd })_{2}\right]^{2+}$ and the leucoverdazyl anion ligands in $\left[\mathrm{Pd}(\mathrm{iPrpyvd})_{2}\right]^{2+}$ reported by Hicks et al. ${ }^{27}$ Similarly the $\mathrm{C}=\mathrm{O}$ stretching frequency, while lower than that for the neutral ligand, is not as low as an anionic ligand. ${ }^{27}$ Consequently a description of this molecule in which the additional electron is delocalized over both ligands (i.e. a mixed valence system) is more appropriate. The large separation between successive one-electron reduction potentials $(0.6 \mathrm{~V})$ is also consistent with delocalized orbitals spanning both ligands. The simplest such model would be high spin $\mathrm{Fe}^{2+}\left(\mathrm{d}^{6}, \mathrm{~S}=2\right)$ ion, ferromagnetically coupled to an overall $S=1 / 2$ delocalized, mixed-valence ligand system. The NIR band can then be considered an intervalence charge transfer (IVCT) band. In terms of the Robin-Day classification, the single $\mathrm{C}=\mathrm{O}$ stretch in the IR places the ligand system as either class III or class II/III, but such a delocalized ligand system initially seems inconsistent with two perpendicular ligands. What mechanism allows the additional electron to be delocalized across both ligands? Furthermore, why is the coupling between radical ligand and metal strongly ferromagnetic when other pi-radical ligands coordinated to high spin $\mathrm{Fe}^{2+}$ show antiferromagnetic coupling. ${ }^{29,} 30$ The key to both of these issues is in the asymmetric distribution of the unpaired electron in the ligand SOMO. ESR measurements on dipyvd itself indicate significant spin density on the N5-pyridyl nitrogen but not on N3pyridyl ring. ${ }^{25}$ Orbitals on the N5-pyridine of both ligands can interact with the metal $d_{\mathrm{xy}}$ orbital providing a pathway for delocalization across the entire system. Direct involvement of the metal orbitals in this way adds further ambiguity in terms of a discrete oxidation state for the metal ion, thus a more useful description might be a series of resonance structures involving $d^{b}, d^{6}$ and $d^{7}$ configurations of the metal center. (Figure 6) The observed ferromagnetic exchange can then be understood as a form of double exchange or spindependent delocalization. ${ }^{31}$ In order for the additional electron to be delocalized over the whole metal-ligand system it must have the opposite spin of both the unpaired electrons on the metal, and the remaining ligand unpaired electron, effectively forcing ferromagnetic alignment of the two (Figure 6). This interpretation is supported by the results of DFT calculations which place the bulk of the spin density on the metal ion, but leave part of it delocalized across both ligands (Figure 5). We note that this is similar to the mechanism invoked to explain the long range coupling of two nitronyl-nitroxides coordinated to a metal center ${ }^{32}$ and the exchange between metal ions in quinonoid bridged systems. ${ }^{14}, 15,33$

To further examine this phenomenon we can compare this to related redox active iron'pincer ligand' systems. Various comparable ligands are shown in chart 1. Electrochemical data for several systems are graphically compared in figure 7 This figure clarifies how $\left[\mathrm{Fe}(\text { dipyvd })_{2}\right]^{2+}$ differs from these structurally similar species. In particular, for most of them the potential of the metal-based $2+/ 3+$ couple and the ligand-based $1+/ 2+$ couple are 
strongly correlated. The potential of the $1+/ 2+$ couple reflects the electron deficiency of the ligand, but also, more electron deficient ligands withdraw electron density from the metal ion, resulting in a higher oxidation potential for the metal. In fact, even though the oxidation potentials of these species vary over a range of $\sim 0.7 \mathrm{~V}$, the difference between first oxidation potential and reduction potential is relatively constant and close to $2.25 \mathrm{~V}$. The position of the strong metal-ligand charge transfer band (characteristic of Fe imine systems) is also largely independent of ligand. This might be expected since this transition corresponds to the simultaneous oxidation of the metal ion and reduction of the ligand.

With the exception of $\left[\mathrm{Fe}(\text { dipyvd })_{2}\right]^{\mathrm{n}+}$ and $\left[\mathrm{Fe}(\mathrm{PDI})_{2}\right]^{\mathrm{n}+}$, successive reduction potentials of the two ligands are within $0.2 \mathrm{~V}$. Though care should be taken in interpreting this gap, it is consistent with largely independent reduction of each ligand with the additional electron being localized on a single ligand. In fact, in the bis tetrazane system $\left[\mathrm{Fe}(\mathrm{bptz})_{2}\right]^{+}$, the localization of the additional electron on a single ligand was firmly established by ESR. ${ }^{19}$ The contrast with the dipyvd complex is striking. Reduction of $\left[\mathrm{Fe}(\text { dipyvd })_{2}\right]^{2+}$ occurs at a much higher potential than the other systems but the metal centered $2+/ 3+$ oxidation is at almost the same potential as for $\left[\mathrm{Fe}(\text { terpy })_{2}\right]^{2+}$. This is a result of the ability of radical ligands to act as both donor and acceptor. 6-oxoverdazyls are typically reduced at $\sim-1 \mathrm{~V}$ vs SCE; lower than the the most electron deficient ligand in this series, bptz ( $-0.86 \mathrm{~V}$ vs SCE), but 6-oxoverdazyls can also undergo one electron oxidation (typically around $0.6 \mathrm{Vvs} \mathrm{SCE}$ ). Cooordination to a positively charged metal ion lowers the energy of the SOMO facilitating ligand reduction; however this also increases back donation from the ligand SOMO to the metal ion, resulting in a comparatively low oxidation potential for the metal center.

Since the properties of $\left[\mathrm{Fe}(\text { dipyvd })_{2}\right]^{\mathrm{n}+}$ seem to arise from the partly filled nature of the ligand orbitals, it is worthwhile to make comparisons with the reduced states of the compounds in figure 6 . Of these, $\left[\mathrm{Fe}(\text { terpy })_{2}\right]^{\mathrm{nt}}$ and $\left[\mathrm{Fe}(\mathrm{MeOPDI})_{2}\right]^{\mathrm{n}+}$ have been more thoroughly studied in reduced states. The doubly reduced species, $\left[\mathrm{Fe}(\text { terpy })_{2}\right]^{0}$ and $\left[\mathrm{Fe}(\mathrm{MeOPDI})_{2}\right]^{0}$ have a high spin $\mathrm{Fe}^{2+}\left(d^{8}, \mathrm{~S}=2\right)$ metal center coordinated to two radicalanion ligands. ${ }^{16,17,34}$ However, without a delocalized mixed-valence ligand system, the double exchange mechanism observed in $\left[\mathrm{Fe}(\text { dipyvd })_{2}\right]^{+}$is not available and overlap of the ligand SOMOs with the $d_{\pi}$ manifold on the metal ion results in strong antiferromagnetic coupling and an $\mathrm{S}=1$ ground state. Further reduction of $\left[\mathrm{Fe}(\text { terpy })_{2}\right]^{0}$ is possible and should lead to a mixed valence ligand system comparable to $\left[\mathrm{Fe}(\text { dipyvd })_{2}\right]^{+}$however such highly reduced species are typically very air sensitive and challenging to characterize. Nevertheless computational results and limited experimental data suggests that in contrast to $\left[\mathrm{Fe}(\text { dipyvd })_{2}\right]^{+},\left[\mathrm{Fe}(\text { terpy })_{2}\right]^{-}$has an $S=1 / 2$ ground state. ${ }^{16}$ Wieghardt suggested that the latter results from coordination of the terpy ${ }^{2-}$ ligand as a triplet, and subsequent strong antiferromagnetic exchange between metal and ligands. This is possible because of the closely spaced antibonding orbitals in terpy. The lack of multiple low lying orbitals in dipyvd $^{-}$combined with delocalization across both ligands results in the observed ferromagnetic exchange. 


\section{Conclusions}

The two ions $\left[\mathrm{Fe}(\text { dipyvd })_{2}\right]^{+}$and $\left[\mathrm{Fe}(\text { dipyvd })_{2}\right]^{2+}$ form a remarkable switchable system. Though the exchange both ions is ferromagnetic, in $\left[\mathrm{Fe}(\operatorname{dipyvd})_{2}\right]^{2+}$ it is small enough that at ambient temperatures the relative population of singlet and triplet states is little different from a diradical. One electron reduction results in a very large increase in magnetic moment resulting from the spin crossover of the iron center combined with a very strong ferromagnetic interaction with the remaining ligand based unpaired electron. The reduction occurs at a relatively high potential such that both $\left[\mathrm{Fe}(\operatorname{dipyvd})_{2}\right]^{+}$and $\left[\mathrm{Fe}(\text { dipyvd })_{2}\right]^{2+}$ are stable under ambient conditions. Furthermore the spin dependent delocalization of the additional electron suggests possible application as a molecular spin valve or a component in other spintronic applications.

\section{Experimental Section}

\section{General}

1-isopropyl-3,5-di(2' -pyridyl)-6-oxo-tetrazane was synthesized using literature methods. ${ }^{25}$ NMR spectra were recorded on a $300 \mathrm{MHz}$ instrument and are referenced to tetramethyl silane. Spectroelectrochemical measurements utilized a $2 \mathrm{~mm}$ pathlength cell, platinum honeycomb working electrode and $\mathrm{Ag} / \mathrm{AgCl}$ pseudoreference that was calibrated before and after measurement with ferrocene. The working electrode was stepped through $0.02 \mathrm{~V}$ increments and allowed to equilibrate for $30 \mathrm{~s}$ at each voltage before a spectrum was recorded. Magnetic susceptibility measurements were recorded between 5 and $300 \mathrm{~K}$ using a vibrating sample magnetometer with an applied field of 3000G. Density functional calculations used the Orca package. ${ }^{35}$ Molecular geometries determined through crystallography were optimized using the BP-86 functional with the def2-TZVP ${ }^{36}$ basis and def $2 / \mathrm{J}^{37}$ auxilliary basis. Subsequent time dependent DFT (TDDFT) calculations used the same basis set and B3LYP hybrid functional.

\section{1-isopropyl-3,5-di(2' -pyridyl)-6-oxo-2H-tetrazine (2)}

1-isopropyl-3,5-di(2' -pyridyl)-6-oxo-tetrazane (1, $2.95 \mathrm{~g}, 10 \mathrm{mmol})$ was dissolved in 400 $\mathrm{mL}$ distilled water. To this solution was added a solution of $2.14 \mathrm{~g}(10 \mathrm{mmol})$ sodium periodate in $30 \mathrm{~mL}$ distilled water. The solution immediately turned orange. After stirring for $10 \mathrm{~min}$, the solution was extracted with $2 \times 200 \mathrm{~mL}$ portions of ethyl acetate and the organic extract was dried and evaporated to give the crude product as an orange oil. This was further purified by dissolution in dichloromethane, filtration through silica gel and evaporation to give an oil that crystallized on standing. (1.68 g, 57\%). ${ }^{1} \mathrm{H}-\mathrm{NMR}(300 \mathrm{MHz}$; $\mathrm{CDCl}_{3}$ ): $\delta 10.74(\mathrm{~s}, 1 \mathrm{H}), 8.67$ (ddd, $\left.J=4.9,1.4,0.8 \mathrm{~Hz}, 1 \mathrm{H}\right), 8.40-8.37(\mathrm{~m}, 1 \mathrm{H}), 8.27$ (d, $J$ $=8.7 \mathrm{~Hz}, 1 \mathrm{H}), 8.10(\mathrm{~d}, J=8.0 \mathrm{~Hz}, 1 \mathrm{H}), 7.81-7.75(\mathrm{~m}, 1 \mathrm{H}), 7.69-7.63(\mathrm{~m}, 1 \mathrm{H}), 7.36$ (dddd, $J$ $=7.5,4.9,1.2,0.5 \mathrm{~Hz}, 1 \mathrm{H}), 7.00-6.95(\mathrm{~m}, 1 \mathrm{H}), 4.72(7, J=6.6 \mathrm{~Hz}, 1 \mathrm{H}), 1.38(\mathrm{~d}, J=6.6 \mathrm{~Hz}$, $6 \mathrm{H}),{ }^{13} \mathrm{C}$ NMR $\left(75 \mathrm{MHz} ; \mathrm{CDCl}_{3}\right): \delta$ 150.4, 149.2, 148.7, 147.9, 147.4, 146.5, 138.0, 136.6, 124.8, 120.8, 118.0, 113.2, 47.9, 20.1; IR (ATR) 3253 (N-H), 2974, 2929, 1683 (C=O), 1651 $(\mathrm{C}=\mathrm{N}), 1587,1568,1461,1431,1364,1253,1186 \mathrm{~cm}^{-1}$; MS (EI) $296(\mathrm{M}+), 197,121,105$, $94,78$. 


\section{$\left[\mathrm{Fe}(\text { dipyvd) }]^{+} \mathrm{PF}_{6}^{-}\right.$}

1-isopropyl-3,5-di(2' -pyridyl)-6-oxo-2H-tetrazine (2, $130 \mathrm{mg}, 0.44 \mathrm{mmol})$ was dissolved in $5 \mathrm{~mL}$ methanol. To this solution was added a solution of ferric ammonium sulfate (106 mg, $0.22 \mathrm{mmol})$ in water $(5 \mathrm{~mL})$. The solution immediately turned deep brown. Excess ammonium hexafluorophosphate dissolved in water $(1 \mathrm{~mL})$ was then added and the resulting brown precipitate removed by vacuum filtration, washed with water and dried to give [Fe(dipyvd) $]^{+} \mathrm{PF}_{6}{ }^{-}(125 \mathrm{mg}, 71 \%)$. IR (ATR) $1674 \mathrm{~cm}^{-1}(\mathrm{C}=\mathrm{O})$; anal:C 44.55, H 3.83, N 20.95; calcd for $\mathrm{C}_{30} \mathrm{H}_{30} \mathrm{FeN}_{12} \mathrm{O}_{2} \bullet\left(\mathrm{PF}_{6}\right) \cdot \mathrm{H}_{2} \mathrm{O}: \mathrm{C}, 44.51 ; \mathrm{H}, 3.98 ; \mathrm{N}, 20.76$; Single crystals were grown through slow diffusion of ether vapor into an acetonitrile solution to give deep brown needles. A crystal was selected and mounted using a small amount of Parabar 10312 oil to a MiTeGen MicroMount, then transferred to the goniometer of a Bruker D8 VENTURE diffractometer. The diffractometer was fitted with an Oxford Cryosystems Cryostream 800 low-temperature device operating at $100 \mathrm{~K}$. Data collection and processing employed APEX $3^{38}$ After indexing on a series of reflections, the crystal class was determined to be body-centered tetragonal. Structure solution was performed with SHELXT.

${ }^{39}$ Refinement was completed with SHELXL. ${ }^{40}$ There was evidence for merohedral twinning, twin law $(010,100,00-1)$. The twin ratio was determined to be 0.3309(14).

Crystal Data: $\mathrm{C}_{34} \mathrm{H}_{36} \mathrm{~F}_{6} \mathrm{FeN}_{14} \mathrm{O}_{2} \mathrm{P}, M=873.59$, tetragonal $a=16.3724(2) \AA, c=14.2233(2) \AA$, $V=3812.63(11) \AA^{3}, Z=4$, space group (No. 82). 28554 reflections were measured of which 9820 were unique. $\left(R_{\text {int }}=0.054\right)$ Solution and refinement gave $R\left(F_{\mathrm{o}}\right)=0.0394(F>2 \sigma(F))$ $R_{W}\left(\mathrm{~F}_{\mathrm{o}}{ }^{2}\right)=0.0982$ (all reflections). The asymmetric unit consists of $1 / 2$ cation complex, $1 / 2$ hexafluorophosphate anion, and one molecule of acetonitrile. A crystallographic two-fold axis passes through $\mathrm{Fe} 1$ of the complex cation, and a second axis passes through P1, F3 and F4 of the anion. Full details of the structure determination have been deposited at the Cambridge Crystallographic Data Center in .cif format, deposition number 1820962.

A Curie plot of the magnetic susceptibility data ( $\chi$ vs. $1 / T)$ was essentially linear $\left(R^{2}=\right.$ 0.997). Data recorded above $50 \mathrm{~K}$ (to avoid the effects of intermolecular interaction) was fitted to a simple linear (Curie) model giving a Curie constant $C=4.29$ and a diamagnetic correction $\chi_{\text {dia }}=0.0028$ (encompassing the diamagnetism of both sample and sample holder). Assuming $S=5 / 2$ the Curie constant gives $g=1.981$. Subsequently this value of $\chi_{\text {dia }}$ was subtracted from the suceptibility data to give $\chi_{\text {para }}$. Plots of $\chi_{\text {para. }} T$ vs. $T$ (presented in the text) illustrate a weak antiferromagnetic interaction at low temperature not apparent in the plot of $\chi$ vs. $1 / T$.

\section{$\left[\mathrm{Fe}(\operatorname{dipyvd})_{2}\right]^{2+}\left(\mathrm{PF}_{6}{ }^{-}\right)_{2}$}

[Fe(dipyvd $\left.)_{2}\right]^{+} \mathrm{PF}_{6}{ }^{-}(24 \mathrm{mg}, 0.03 \mathrm{mmol})$ was dissolved in dichloromethane $(1 \mathrm{~mL})$ To this deep brown solution was added a solution of $\mathrm{AgPF}_{6}(8 \mathrm{mg}, 0.03 \mathrm{mmol})$ in dichloromethane $(1 \mathrm{~mL})$. After approx. $1 \mathrm{~min}$ a dark precipitate of $\left[\mathrm{Fe}(\mathrm{dipyvd})_{2}\right]^{2+}\left(\mathrm{PF}_{6}{ }^{-}\right)_{2}$ began to form. This was removed by filtration, redissolved in acetone, the solution filtered to remove metallic silver and the solvent evaporated. The product was a deep red-brown crystalline solid (13 mg, 48\%) with IR (ATR) $1725 \mathrm{~cm}^{-1}(\mathrm{C}=\mathrm{O})$; anal. found: C: $38.43, \mathrm{H} 3.13, \mathrm{~N}$ 18.20, calcd for $\mathrm{C}_{30} \mathrm{H}_{30} \mathrm{FeN}_{12} \mathrm{O}_{2} \bullet\left(\mathrm{PF}_{6}\right)_{2} \mathrm{C}: 38.48, \mathrm{H}: 3.23$, N: 17.95. Dark red single crystals were grown from diffusion of ether into an acetonitrile solution. Intensity data were 
collected at $150 \mathrm{~K}$ on a Bruker SMART CCD system. Solution and refinement used the program Olex $2^{41}$ along with the SHELX software suite. Crystal data: $\mathrm{C}_{32} \mathrm{H}_{33} \mathrm{~F}_{12} \mathrm{FeN}_{13} \mathrm{O}_{2} \mathrm{P}_{2}$, Triclinic, $a=8.4972(14), b=14.741, c=16.340(3), a=73.026(2), \beta=81.584(2), \gamma=87.250(2)$. $V=1936.3(5), Z=2$, space group (No. 2). 17668 independent reflections were measured, of which 7042 were unique. $\left(R_{\text {int }}=0.03\right)$. Solution and refinement gave $R\left(F_{\mathrm{o}}\right)=0.0515(F)$ $2 \sigma(F)) R_{W}\left(\mathrm{~F}_{\mathrm{o}}{ }^{2}\right)=0.1412$ (all reflections). Details of data collection, solution, and refinement have been deposited at the Cambridge Crystallographic Data Center in .cif format, deposition number 1820797.

A second batch of crystals was grown from acetone/ethanol. A sample for crystallographic analysis was submitted through the Service Crystallography at Advanced Light Source (SCrALS) program at Lawrence Berkeley National Laboratory. Intensity data were collected at $150 \mathrm{~K}$ on a D8 goniostat equipped with a Bruker PHOTON100 CMOS detector at Beamline 11.3.1 at the Advanced Light Source using synchrotron radiation tuned to $\lambda=$ $0.7749 \AA$ A. For data collection frames were measured for a duration of 6 -s at $0.5^{\circ}$ intervals of $\omega$. The data frames were collected using the program APEX $2^{42}$ and processed using the SAINT $^{43}$ routine within APEX2. The data were corrected for absorption and beam corrections based on the multi-scan technique as implemented in SADABS. ${ }^{44}$ Solution and refinement used the program Olex $2^{41}$ along with the SHELX software suite. Crystal Data: $\mathrm{C}_{30} \mathrm{H}_{30} \mathrm{~F}_{12} \mathrm{FeN}_{12} \mathrm{O}_{2} \mathrm{P}_{2}, M=936.43$, tetragonal $a=15.8913(15), c=14.8198(16)$, $V=3742.5(6) \AA^{3}, Z=4$, space group (No. 82). 27667 independent reflections were measured, of which 1985 were unique. $\left(R_{\mathrm{int}}=0.1032\right)$. Solution and refinement gave $R\left(F_{\mathrm{0}}\right)=0.0539$ (F> $2 \sigma(F)) R_{W}\left(\mathrm{~F}_{\mathrm{o}}^{2}\right)=0.1589$ (all reflections). Details of data collection, solution, and refinement have been deposited at the Cambridge Crystallographic Data Center in .cif format, deposition number 1824292.

The MATLAB optimization toolbox ${ }^{45}$ was used to fit magnetic susceptibility to the BleaneyBowers dimer model with a correction, $J^{\prime} / T$ for intermolecular interaction at low temperature. The intramolecular magnetic exchange $J$, diamagnetic correction $\chi_{\text {dia, }}$ (encompassing the diamagnetism of both sample and sample holder) and intermolecular exchange $J^{\prime}$ were used as fitting parameters. The best fit gave $J=-145(2) \mathrm{cm}^{-1}, J^{\prime}=1.28(1)$ $\mathrm{cm}^{-1}$ and $\chi_{\text {dia }}=0.00464$ (2) with $R=0.018$. Subsequently this value of $\chi_{\text {dia }}$ was used to calculate $\chi_{\text {para. }}$. Plots of $\chi_{\text {para }} T$ vs. $T$ are presented in the text to better illustrate the temperature dependence of the paramagnetic term.

\section{Supplementary Material}

Refer to Web version on PubMed Central for supplementary material.

\section{Acknowledgments}

Financial support for this research was provided by the National Science Foundation (grant CHE-1058077 to DJRB), SJSU undergraduate research grants (to CF and DC), and the NIH-MBRS RISE program (5R25GEMO71381). Crystallographic data for the tetragonal form of [Fe(dipyvd)2].( $\left.\mathrm{PF}_{6}\right)_{2}$ were collected through the SCrALS (Service Crystallography at Advanced Light Source) program at the Small-Crystal Crystallography Beamline 11.3.1 at the Advanced Light Source (ALS), Lawrence Berkeley National Laboratory. The ALS is supported by the U.S. Department of Energy, Office of Energy Sciences Materials Sciences Division, under contract DE-AC02-05CH11231. DFT calculations utilized the SJSU high performance computational cluster supported by National Science Foundation grant MRI-1626645. 


\section{Notes and References}

1. Zhang JL, Zhong JQ, Lin JD, Hu WP, Wu K, Xu GQ, Wee ATS, Chen W. Chem Soc Rev. 2015; 44:2998-3022. [PubMed: 25757483]

2. Green JE, Choi J Wook, Boukai A, Bunimovich Y, Johnston-Halperin E, DeIonno E, Luo Y, Sheriff BA, Xu K, Shik Shin Y, Tseng H-R, Stoddart JF, Heath JR. Nature. 2007; 445:414. [PubMed: 17251976]

3. Gütlich, P. Structure and Bonding. Vol. 44. Springer Verlag; New York: 1981. 85-195.

4. Gutlich P, Garcia Y, Goodwin HA. Chem Soc Rev. 2000; 29:419-427.

5. Tezgerevska T, Alley KG, Boskovic C. Coord Chem Rev. 2014; 268:23-40.

6. Gutlich P, Hauser A. Coord Chem Rev. 1990; 97:1-22.

7. Pierpont CG. Coord Chem Rev. 2001; 219-221:415-433.

8. Pierpont CG. Coord Chem Rev. 2001; 216-217:99-125.

9. Nishida S, Morita Y, Fukui K, Sato K, Shiomi D, Takui T, Nakasuji K. Angew Chem-Int Edit. 2005; 44:7277-7280.

10. Ishiguro K, Ozaki M, Sekine N, Sawaki Y. J Am Chem Soc. 1997; 119:3625-3626.

11. Haller BC, Chambers D, Cheng R, Chemistruck V, Hom TF, Li Z, Nguyen J, Ichimura A, Brook DJR. J Phys Chem A. 2015; 119:10750-10760. [PubMed: 26451688]

12. Sandberg MO, Nagao O, Wu ZK, Matsushita MN, Sugawara T. Chem Commun. 2008:3738-3740.

13. Ito A, Kurata R, Sakamaki D, Yano S, Kono Y, Nakano Y, Furukawa K, Kato T, Tanaka K. J Phys Chem A. 2013; 117:12858-12867. [PubMed: 24191634]

14. Gaudette AI, Jeon IR, Anderson JS, Grandjean F, Long GJ, Harris TD. J Am Chem Soc. 2015; 137:12617-12626. [PubMed: 26375161]

15. Jeon IR, Sun L, Negru B, Van Duyne RP, Dincă M, Harris TD. J Am Chem Soc. 2016; 138:65836590. [PubMed: 27116424]

16. England J, Scarborough CC, Weyhermüller T, Sproules S, Wieghardt K. Eur J Inorg Chem. 2012; 2012:4605-4621.

17. Wile BM, Trovitch RJ, Bart SC, Tondreau AM, Lobkovsky E, Milsmann C, Bill E, Wieghardt K, Chirik PJ. Inorg Chem. 2009; 48:4190-4200. [PubMed: 19035761]

18. Kershaw Cook LJ, Tuna F, Halcrow MA. Dalton Transactions. 2013; 42:2254-2265. [PubMed: 23197133]

19. Benson CR, Hui AK, Parimal K, Cook BJ, Chen CH, Lord RL, Flood AH, Caulton KG. Dalton Transactions. 2014; 43:6513-6524. [PubMed: 24623103]

20. Brook DJR. Comments on Inorganic Chemistry. 2015; 35:1-17.

21. Gilroy JB, McKinnon SDJ, Koivisto BD, Hicks RG. Org Lett. 2007; 9:4837-4840. [PubMed: 17927192]

22. McKinnon SDJ, Patrick BO, Lever ABP, Hicks RG. Inorg Chem. 2013; 52:8053-8066. [PubMed: 23789578]

23. McKinnon SDJ, Patrick BO, Lever ABP, Hicks RG. Chem Commun. 2010; 46:773-775.

24. Anderson KJ, Gilroy JB, Patrick BO, McDonald R, Ferguson MJ, Hicks RG. Inorg Chim Acta. $2011 ; 374: 480-488$.

25. Richardson C, Haller B, Brook DJR, Hundley M, Yee GT. Chem Commun. 2010:6590-6592.

26. R. G. Hicks, 2015.

27. Sanz CA, McKay ZR, MacLean SWC, Patrick BO, Hicks RG. Dalton Transactions. 2017; 46:12636-12644. [PubMed: 28913533]

28. Soda T, Kitagawa Y, Onishi T, Takano Y, Shigeta Y, Nagao H, Yoshioka Y, Yamaguchi K. Chem Phys Lett. 2000; 319:223-230.

29. Tondreau AM, Stieber SCE, Milsmann C, Lobkovsky E, Weyhermüller T, Semproni SP, Chirik PJ. Inorg Chem. 2013; 52:635-646. [PubMed: 23268722]

30. Tondreau AM, Milsmann C, Lobkovsky E, Chirik PJ. Inorg Chem. 2011; 50:9888-9895. [PubMed: 21667935]

31. Kahn, O. Molecular Magnetism. VCH; New York: 1993. 
32. Kirk ML, Shultz DA, Schmidt RD, Habel-Rodriguez D, Lee H, Lee J. J Am Chem Soc. 2009; 131:18304-18313. [PubMed: 19928960]

33. DeGayner JA, Jeon IR, Sun L, Dincă M, Harris TD. J Am Chem Soc. 2017; 139:4175-4184. [PubMed: 28230984]

34. de Bruin B, Bill E, Bothe E, Weyhermüller T, Wieghardt K. Inorg Chem. 2000; 39:2936-2947. [PubMed: 11232835]

35. Neese F. Wiley Interdisciplinary Reviews - Computational Molecular Science. 2012; 2:73-78.

36. Weigend F, Ahlrichs R. Phys Chem Chem Phys. 2005; 7:3297. [PubMed: 16240044]

37. Weigend F. Phys Chem Chem Phys. 2006; 8:1057. [PubMed: 16633586]

38. Bruker. APEX3v2017.3-rc2. Bruker AXS Inc; Madison, WI, USA: 2017.

39. Sheldrick G. Acta Crystallographica Section A. 2015; 71:3-8.

40. Sheldrick G. Acta Crystallographica Section C. 2015; 71:3-8.

41. Dolomanov OV, Bourhis LJ, Gildea RJ, Howard JAK, Puschmann H. J Appl Cryst. 2009; 42:339341.

42. Bruker. APEX2 v 2014.11.0. Bruker AXS; Madison WI: 2014.

43. Bruker. SAINT v8.34A. Bruker AXS Inc; Madison, WI, USA: 2014.

44. Sheldrick, GM. SADABS. University of Göttingen; Germany: 1996.

45. MATLAB and Optimization Toolbox Release 2009b. The Mathworks Inc; Natick, Massachusetts, United States: 2009. 

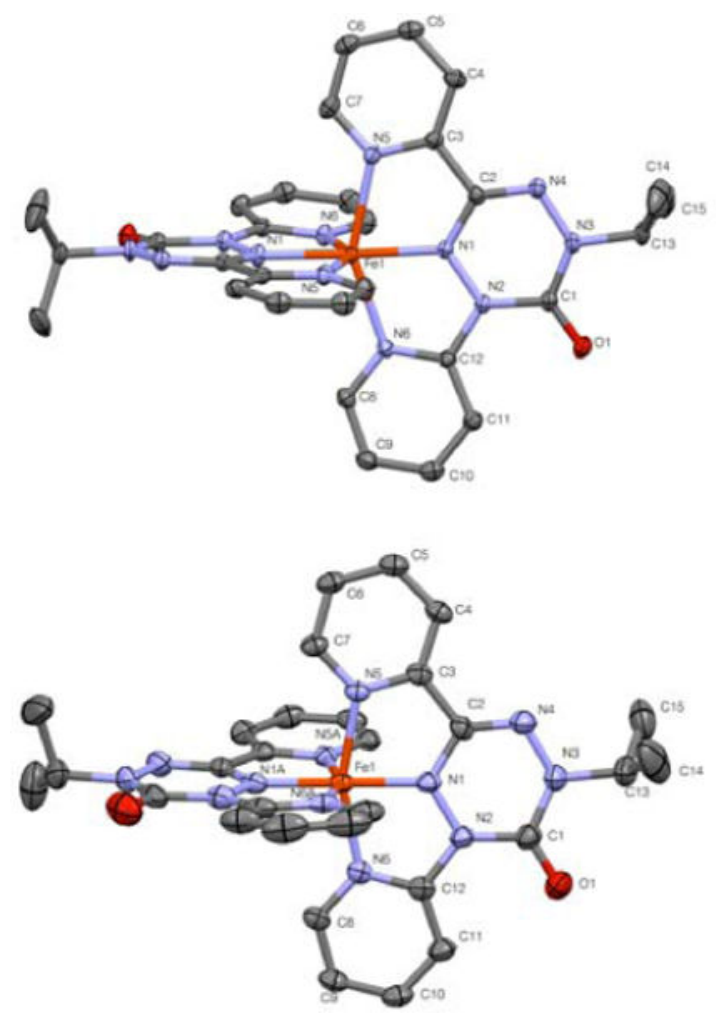

Figure 1.

Thermal ellipsoid plots of cations $\left[\mathrm{Fe}(\text { dipyvd })_{2}\right]^{1+}$ (top) and $\left[\mathrm{Fe}(\text { dipyvd })_{2}\right]^{2+}($ bottom) 


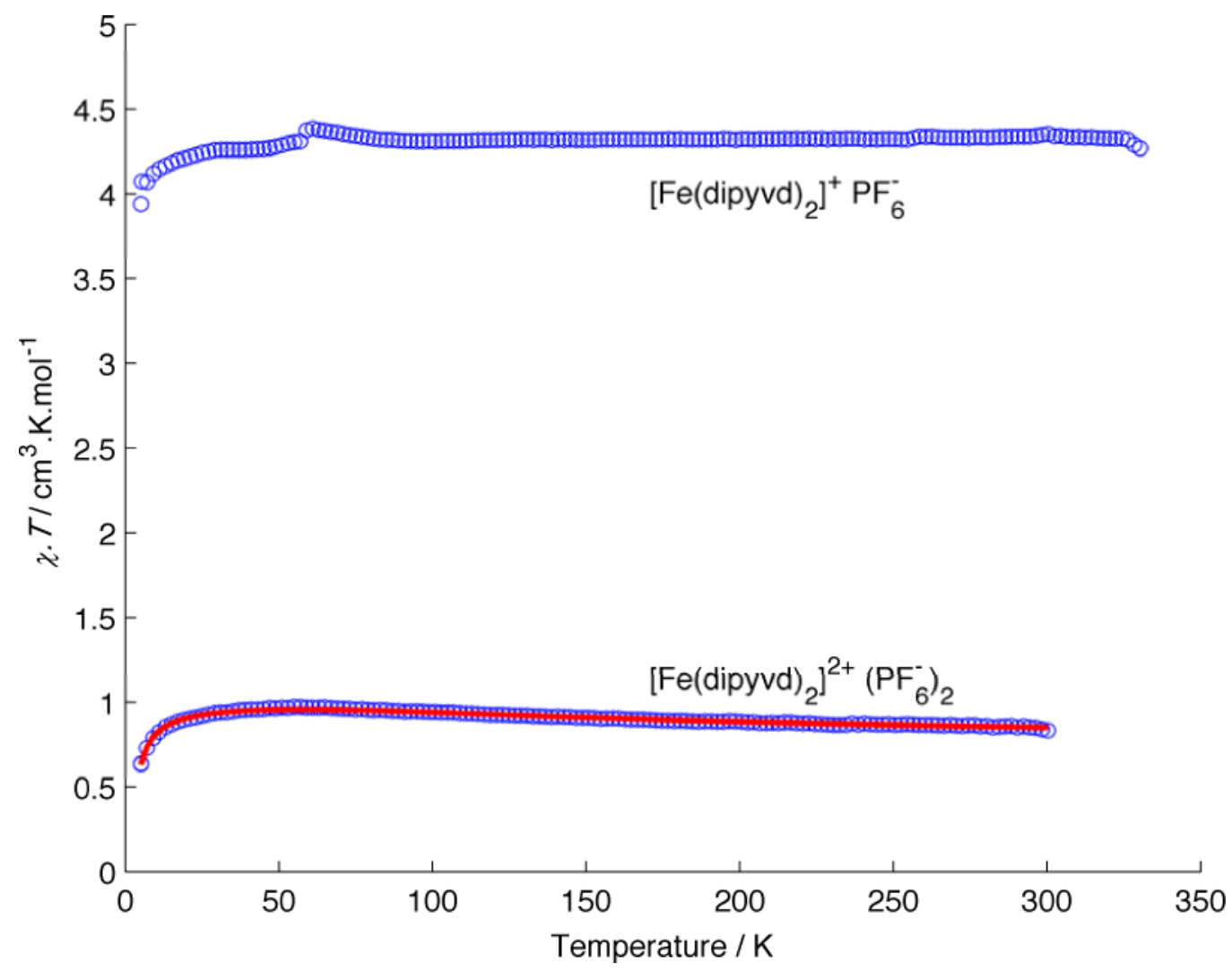

Figure 2.

Plots of $\chi_{\text {para. }} \cdot \mathrm{T}$ vs. $\mathrm{T}$ for $\left[\mathrm{Fe}(\operatorname{dipyvd})_{2}\right]^{1+}$ and $\left[\mathrm{Fe}(\operatorname{dipyvd})_{2}\right]^{2+}$. The solid red line is the best fit to the data for $\left[\mathrm{Fe}(\text { dipyvd })_{2}\right]^{2+}$ (see text). 


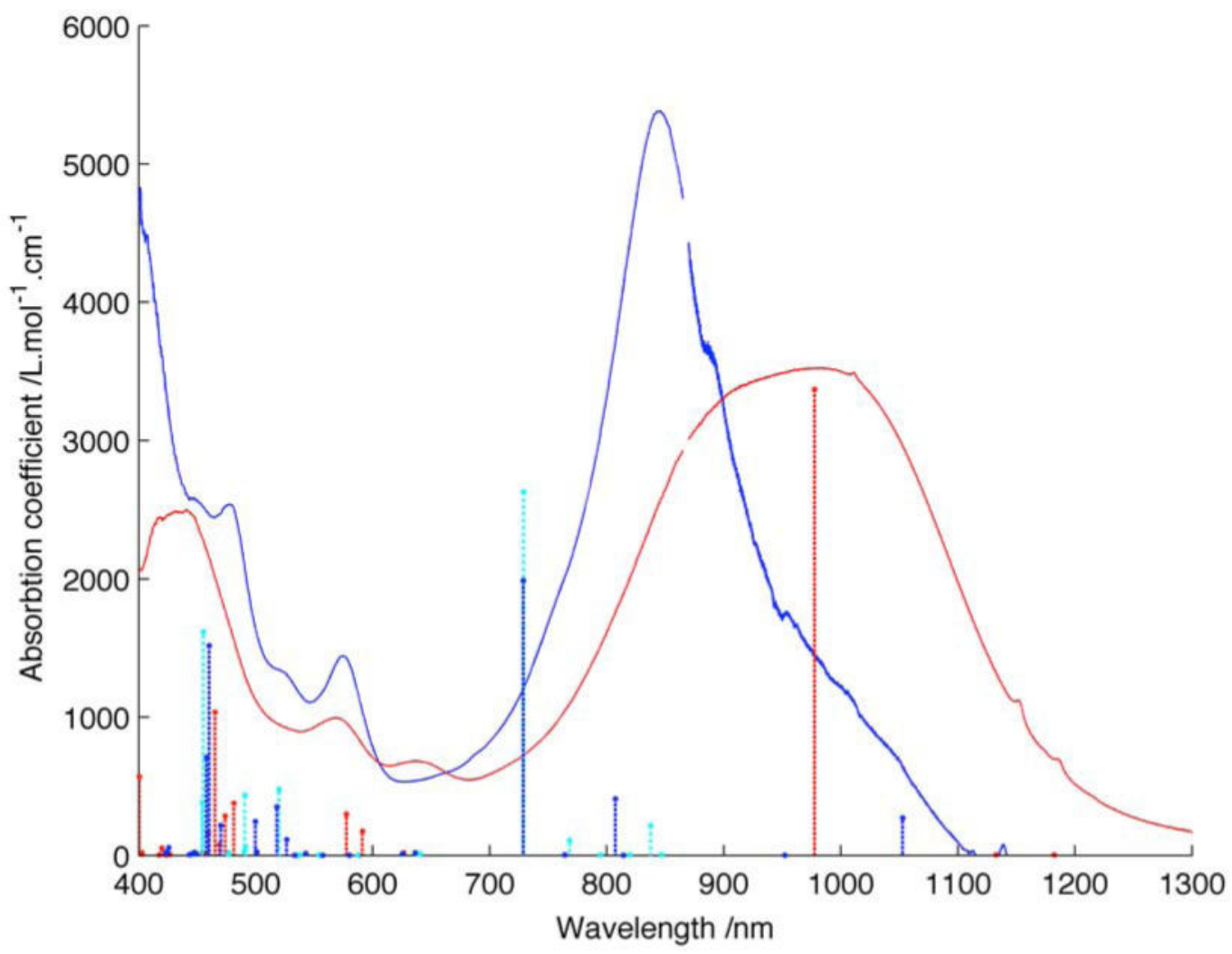

Figure 3.

Electronic spectra of $\left[\mathrm{Fe}(\text { dipyvd })_{2}\right]^{1+}($ red $)$ and $\left[\mathrm{Fe}(\text { dipyvd })_{2}\right]^{2+}($ blue $)$ recorded in acetonitrile. Vertical bars indicate positions and relative intensity of absorbtions calculated using TDDFT. $\left(\right.$ red $\left.\left[\mathrm{Fe}(\operatorname{dipyvd})_{2}\right]^{1+}\right)$, blue $\left(\left[\mathrm{Fe}(\operatorname{dipyvd})_{2}\right]^{2+}\right.$, triplet $),\left(\right.$ cyan $\left[\mathrm{Fe}(\operatorname{dipyvd})_{2}\right]^{2+}$, singlet)). 

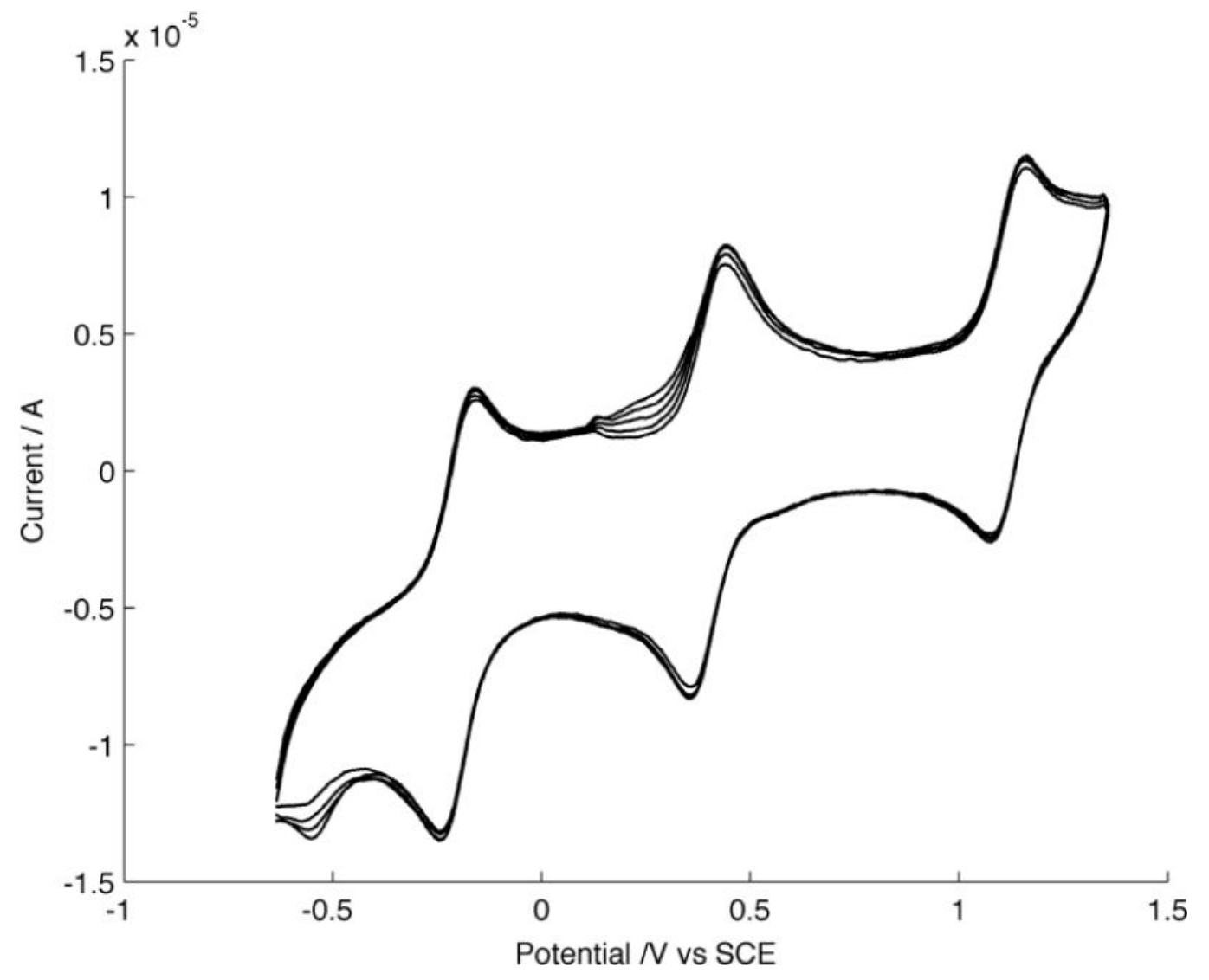

Figure 4.

Cyclic voltammetry trace for $\left[\mathrm{Fe}(\text { dipyvd })_{2}\right]^{0 / 1+/ 2+/ 3+}$ in acetonitrile solvent 

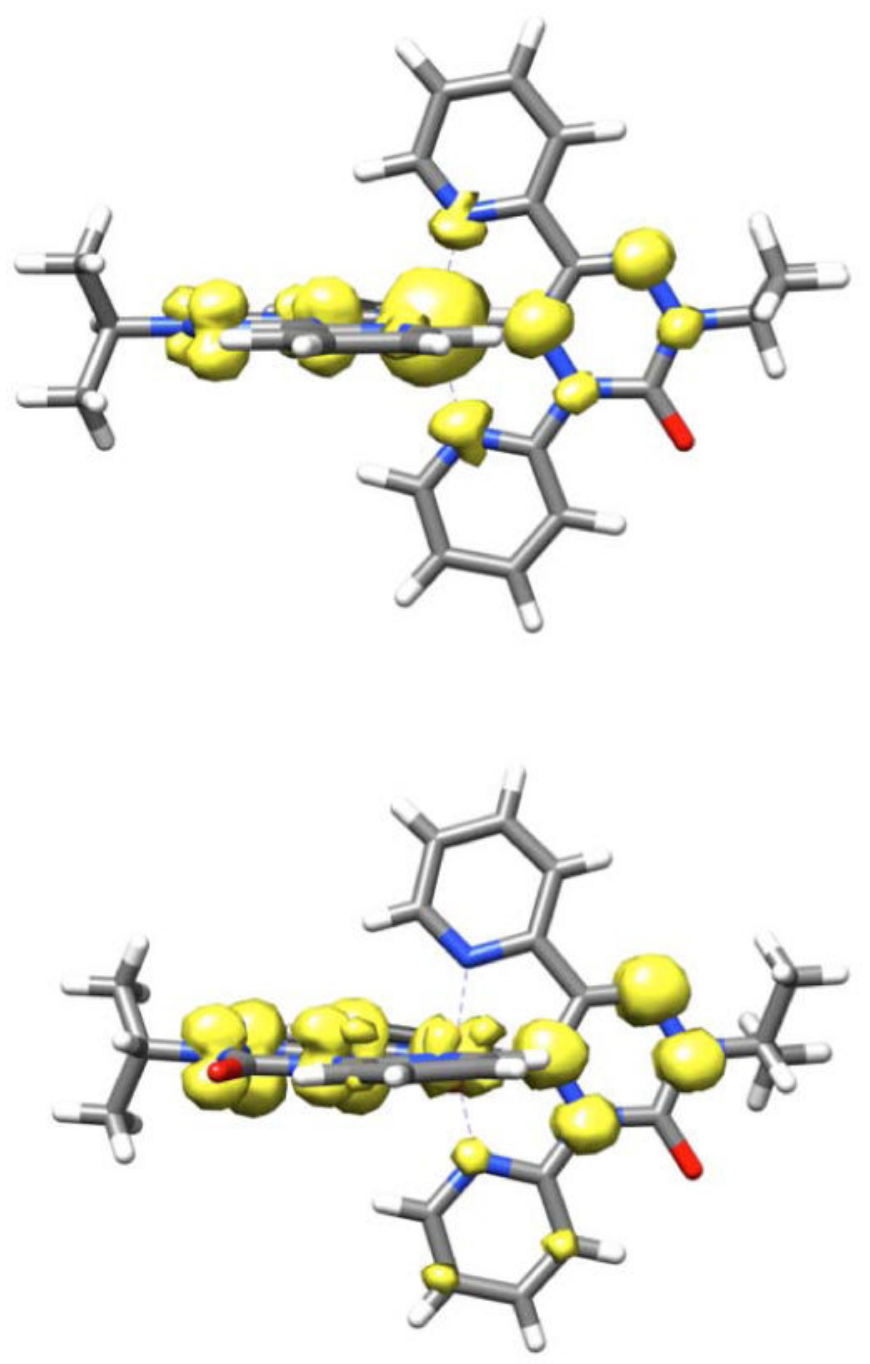

Figure 5.

DFT calculated spin density for $\left[\mathrm{Fe}(\text { dipyvd })_{2}\right]^{1+}($ top $)$ and the triplet state of $\left[\mathrm{Fe}(\text { dipyvd })_{2}\right]^{2+}$ (bottom). 


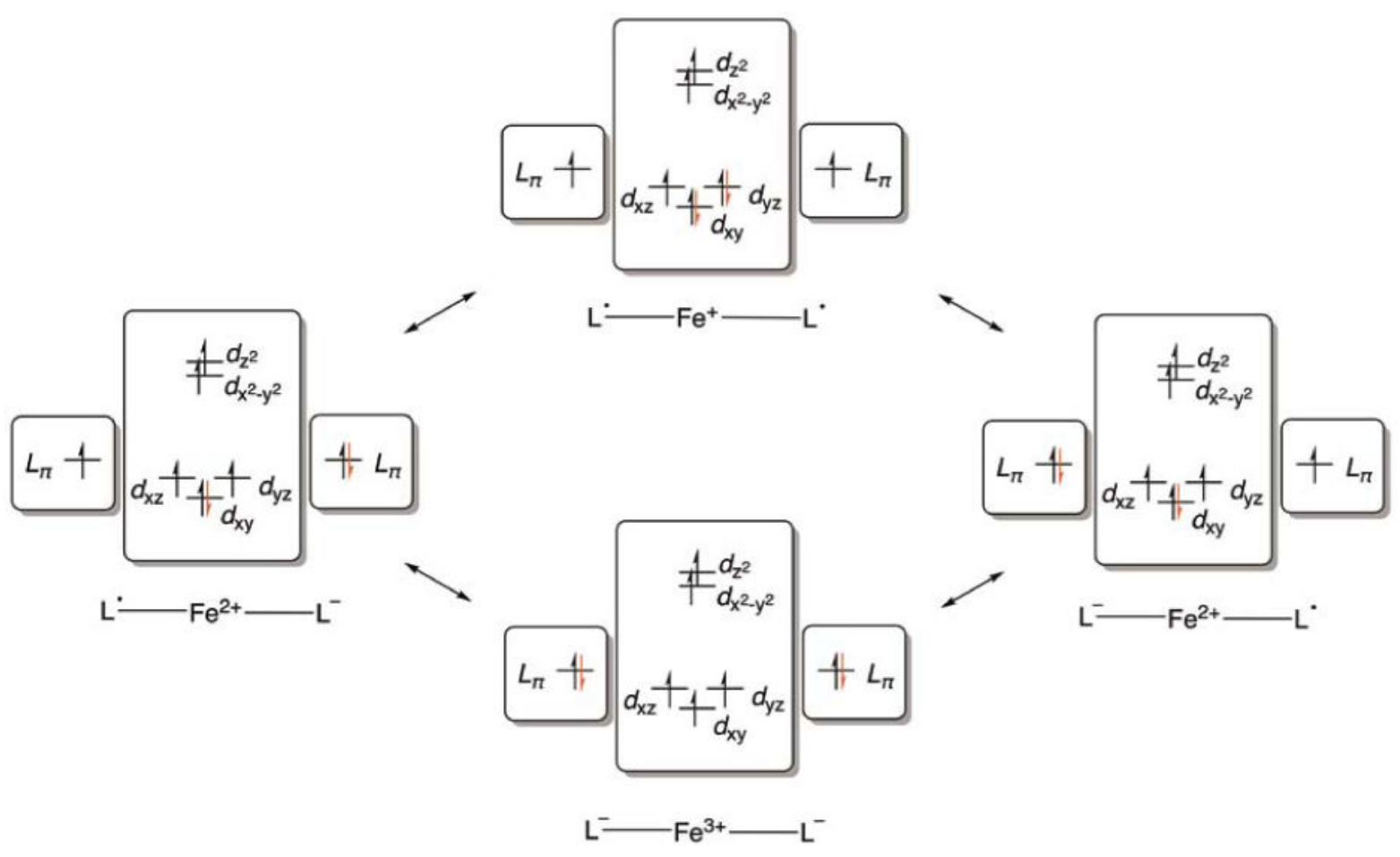

Figure 6.

Spin dependent delocalization resulting in ferromagnetic exchange in $\left[\mathrm{Fe}(\text { dipyvd })_{2}\right]^{+}$ 


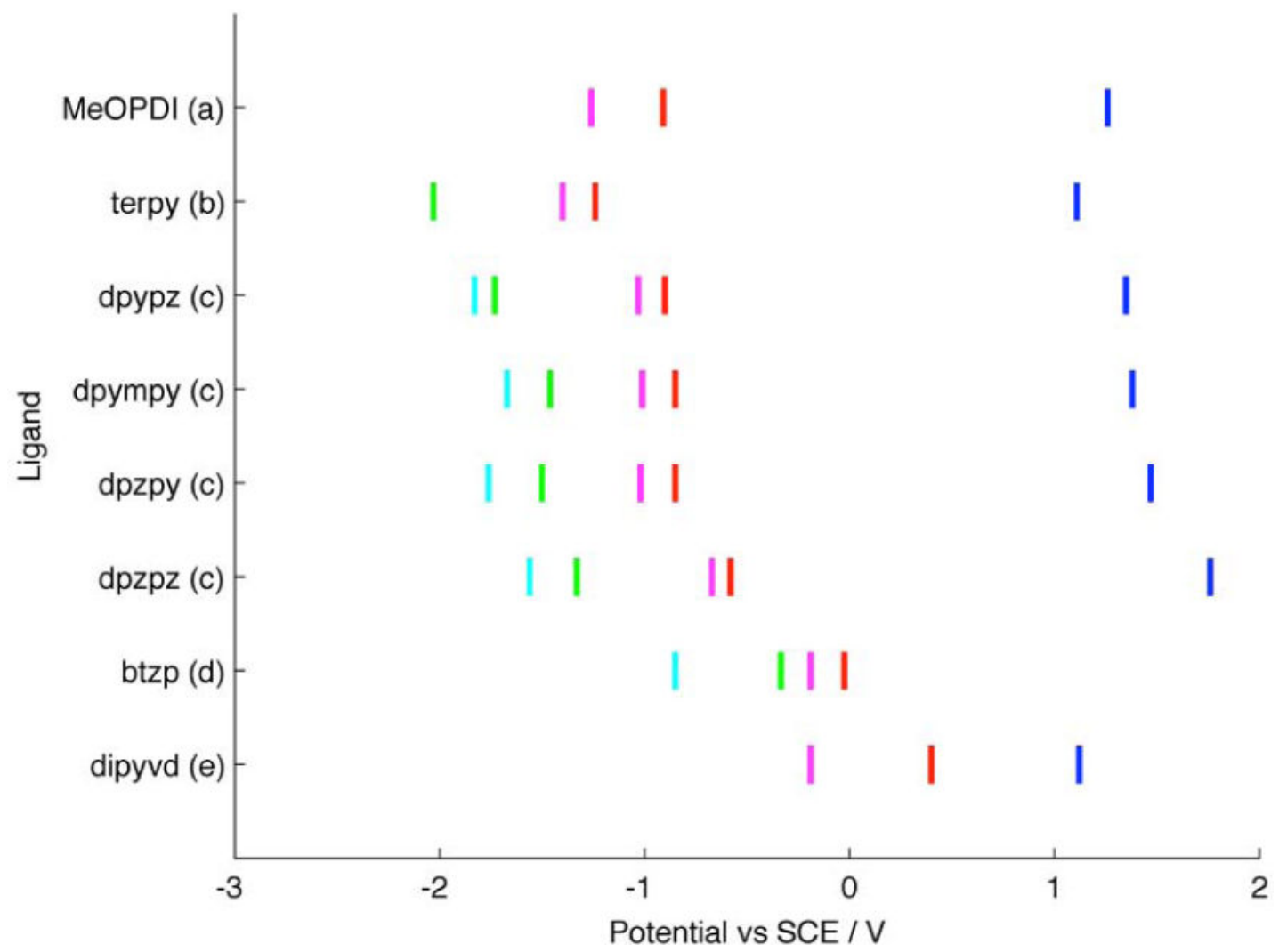

Figure 7.

Redox potentials for iron complexes of the pincer ligands shown in chart 1 . Potentials are coded by color: blue - 3+/2+; red - 2+/1+; magenta - $1+/ 0$; green - 0/1-; cyan 1-/2-. Data taken from a) reference 34, b) reference 16, c) reference 18 , d) reference 19 , e) this work 


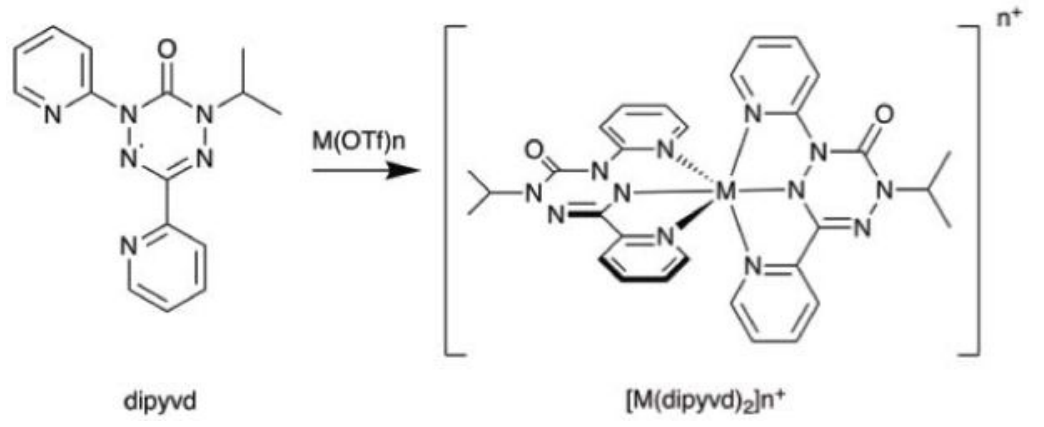

Scheme 1.

Synthesis of dipyvd compounds by direct combination 
<smiles>CC(C)N1NCNN(c2ccccn2)C1=O</smiles>

1<smiles>CC(C)c1ccccn1</smiles>
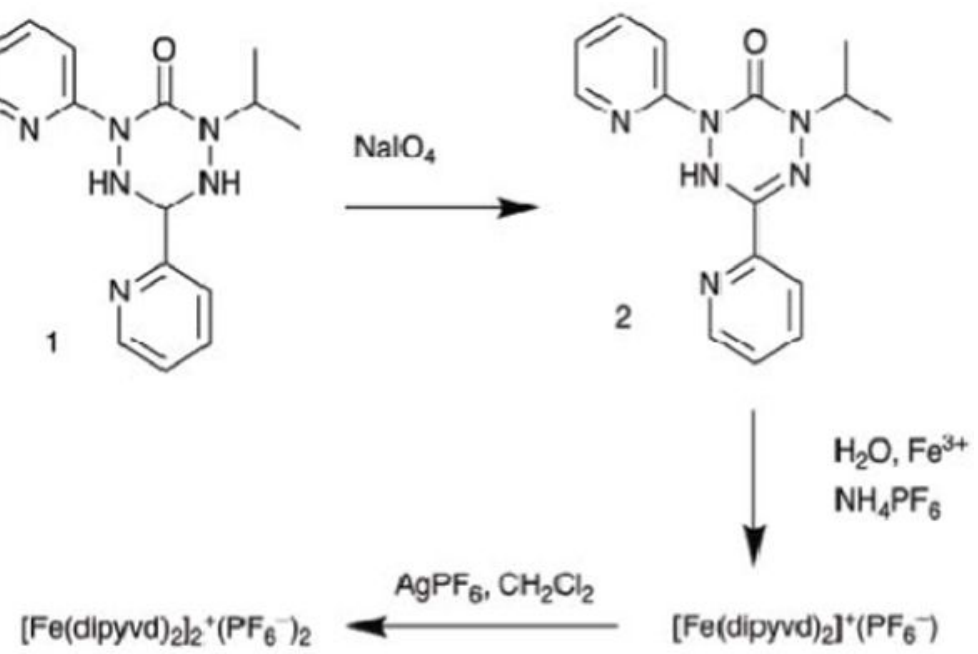

Scheme 2.

Synthesis of leucoverdazyl 2, $\left[\mathrm{Fe}(\text { dipyvd })_{2}\right]^{+} \cdot \mathrm{PF}_{6}{ }^{-}$and $\left[\mathrm{Fe}(\text { dipyvd })_{2}\right]^{2+}\left(\mathrm{PF}_{6}{ }^{-}\right)_{2}$ 
<smiles>c1ccc(-c2cccc(-c3ccccn3)n2)nc1</smiles><smiles>O=C(O)OCc1ccccn1</smiles>

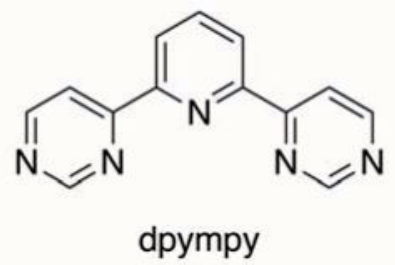<smiles>O=C(O)OC(=O)OCc1cnccn1</smiles><smiles>O=C(OCc1cnccn1)Oc1ccccc1</smiles><smiles>Cc1nnc(-c2cccc(-c3nnc(C)nn3)n2)nn1</smiles><smiles>COc1ccc(/N=C(\C)c2cccc(/C(C)=N/c3ccc(OC)cc3)n2)cc1</smiles>

Chart 1.

Redox active pincer ligands related to dipyvd. 


\section{Table 1}

Selected crystallographic distances for $\left[\mathrm{Fe}(\text { dipyvd })_{2}\right]^{1+} \mathrm{PF}_{6-}$ and $\left[\mathrm{Fe}(\text { dipyvd })_{2}\right]^{2+}\left(\mathrm{PF}_{6-}\right)^{2}$ with values from the leucoverdazyl compound $\left[\mathrm{Pd}(\mathrm{iPrpyvd})_{2}\right]^{2+}\left(\mathrm{BF}_{4-}\right)_{2}{ }^{a}$ for comparison

\begin{tabular}{|c|c|c|c|}
\hline Bond & {$\left[\mathrm{Fe}(\operatorname{dipyvd})_{2}\right]^{+} \mathrm{PF}_{6}^{-}$} & {$[\mathrm{Fe}(\operatorname{dipyvd}) 2]^{2+}\left(\mathrm{PF}_{6}^{-}\right)_{2}$} & {$\left[\operatorname{Pd}(\mathrm{iPrpyvd})_{2}\right]^{2+}\left(\mathrm{BF}_{4}^{-}\right)_{2}{ }^{a}$} \\
\hline Fe-N1 & $1.986(2)$ & $1.842(2), 1.850(3)$ & \\
\hline $\mathrm{Fe}-\mathrm{N} 5$ & $2.171(2)$ & $2.003(2), 1.993(3)$ & \\
\hline Fe-N6 & $2.134(2)$ & $1.978(2), 1.980(3)$ & \\
\hline $\mathrm{N} 1-\mathrm{N} 2$ & $1.399(3)$ & $1.378(4), 1.374(4)$ & $1.428(2)$ \\
\hline $\mathrm{N} 2-\mathrm{C} 1$ & $1.404(3)$ & $1.406(5), 1.406(6)$ & $1.412(2)$ \\
\hline $\mathrm{C} 1-\mathrm{N} 3$ & $1.361(3)$ & $1.372(5), 1.368(5)$ & $1.358(3)$ \\
\hline $\mathrm{N} 3-\mathrm{N} 4$ & $1.392(3)$ & $1.361(4), 1.376(5)$ & $1.414(2)$ \\
\hline $\mathrm{N} 4-\mathrm{C} 2$ & $1.303(3)$ & $1.299(5), 1.312(5)$ & $1.296(2)$ \\
\hline $\mathrm{C} 2-\mathrm{N} 1$ & $1.355(3)$ & $1.345(4), 1.348(4)$ & $1.347(2)$ \\
\hline planarity $b$ & 0.02 & 0.01 & 0.095 \\
\hline
\end{tabular}




\section{Table 2}

Select bond lengths from DFT calculations

\begin{tabular}{lcc}
\hline Bond & $\begin{array}{c}{\left[\mathbf{F e}(\mathbf{d i p y v d})_{2}\right]^{+}} \\
(\mathbf{S = 5} \mathbf{5})\end{array}$ & $\begin{array}{c}{\left[\mathbf{F e}(\mathbf{d i p y v d})_{2}\right]^{2+}} \\
(\mathbf{S = 1})\end{array}$ \\
\hline Fe-N4 & 2.014 & 1.854 \\
Fe-N & 2.173 & 1.989 \\
Fe-N & 2.224 & 2.010 \\
N1-N2 & 1.373 & 1.358 \\
N2-C3 & 1.309 & 1.314 \\
C3-N4 & 1.356 & 1.354 \\
N4-N5 & 1.402 & 1.380 \\
N5-C6 & 1.425 & 1.398 \\
C6-N1 & 1.386 & 1.433 \\
\hline
\end{tabular}

